\title{
Effect of Prevulcanisation Time on the Latex Particles, Surface Morphology and Strength of Epoxidised Natural Rubber Films
}

\author{
Ruslimie C. A., Norhanifah M. Y., Fatimah Rubaizah, M. R. and Asrul M.
}

\begin{abstract}
A preliminary investigation on the use of sulphur vulcanisation system to prevulcanise the Epoxidation Natural Rubber Latex (ENR) is described in the paper. In this study, using a conventional sulphur acceleration system, the prevulcanisation of ENR25 latex was investigated as a function of time. The influence of the prevulcanisation time on the surface morphology, crosslinking and strength of the resulting films was investigated via optical light microscopy, crosslink density and tensile strength measurement respectively. The morphology of unvulcanised and prevulcanised ENR25 latex particles were also compared using Environmental Scanning Electron Microscope (ESEM). Film formation of ENR25 films displayed changes from relatively smoother to coarse and undulate surfaces as prevulcanisation time increases. The results of crosslink density indicated an increment in crosslink formation after 24 hours, whilst it decreases after 48 hours of prevulcanisation time. Similar trend for swelling behaviour of ENR films was also observed. These results suggested that the most obvious influence of prevulcanisation time is the physical property where the increment in tensile strength accompanied longer prevulcanisation time. This increment in strength is particularly obvious at beginning of vulcanisation process, but was decreased after 48 hours. It is clear that the prevulcanisation time for vulcanised ENR25 films have a profound influenced on the film formation and should be controlled to achieve the desirable properties.
\end{abstract}

Keywords - Epoxidised Natural Rubber Latex, Crosslink, Prevulcanisation and Tensile strength.

\section{INTRODUCTION}

$\mathrm{P}$ REVULCANISATION in rubber latex is the process to allow compounded rubber latex to stand for a certain period at normal ambient normal temperature before being used in the process for which it is intended [1]. While Gorton in 1979 described prevulcanisation as a process where raw latex is added with various compounding ingredients such as accelerators, and sulphur until the required degree of

Ruslimie, C. A. is with the Technology \& Engineering Division, Rubber Research Institute Malaysia, Malaysian Rubber Board, 47000, Sg. Buloh, Selangor Darul Ehsan.

Norhanifah, M. Y., is with Technology \& Engineering Division, Rubber Research Institute of Malaysia, Malaysia Rubber Board, 47000, Sg. Buloh, Selangor Darul Ehsan

Fatimah Rubaizah, M. R. is with Technology \& Engineering Division, Rubber Research Institute of Malaysia, Malaysia Rubber Board, 47000, Sg. Buloh, Selangor Darul Ehsan

Asrul, M. is with Technology \& Engineering Division, Rubber Research Institute of Malaysia, Malaysia Rubber Board, 47000, Sg. Buloh, Selangor Darul Ehsan crosslinking is obtained as indicated by the relevant parameters [2]. Compounded latex is usually prevulcanised between 1 to 7 days depending on manufacturer's proprietary process. Commonly, in order to prevent settlement of high densities vulcanisation ingredients the compounded latex is subjected to slow and continuous stirring. At the end of the process, a prevulcanised latex consisting of partial crosslinks is formed and this latex is subsequently used for dipping to make latex dipped products such as gloves, condoms, etc. The prevulcanised latex has a similar appearance to that unvulcanised latex where the former retains the original fluidity, similar latex particles size distribution and stable colloidal characteristic of the latex [3], [4].

The process of prevulcanisation is similar to latex maturation [5]. Nonetheless, the use of the term maturation is preferred in the latex dipped industry to differentiate the process of prevulcanisation and the ready to use latex called the 'prevulcanised latex' available in the market. After prevulcanisation or maturation, the rubber latex is subjected to drying or the process of postvulcanisation used to fully crosslink rubber latex to acquire products. The prevulcanisation process is important to maintain the consistency of quality of the finished latex dipped products. Fully vulcanised films obtained from high ammonia prevulcanised latex exhibited more intraparticles crosslinking occurring within the rubber latex particles and less crosslinking within the particles as demonstrated by Cook et. $a l$, in 1997 [6] using the network visualisation technique via TEM.

During the period of prevulcanisation, certain processes may occur where the surfactants naturally present in latex and those added together as dispersions to equilibrate between the aqueous and interfacial phases [7]. Other occurrence may also occur simultaneously such as the dissolution of sulphur and accelerators in the serum and migration of the vulcanising ingredients into the rubber particles [8]. As such, prevulcanisation depends upon the duration of time and the temperature at which latex is stored.

In most of the work pertaining to the study of prevulcanisation, high ammonia rubber latex is the type of rubber which has been extensively investigated described has been more focused on the prevulcanisation of high ammonia rubber latex. In the present study, a new type of natural rubber latex which is commercially known as Ekoprena ${ }^{\circledR}$ is used. The prevulcanisation parameter for a type of epoxidised natural rubber latex i.e.: ENR25 latex. The conventional 
sulphur vulcanising system for high ammonia rubber latex was used in this study. Hence, the present study provides certain insight on the prevulcanisation of ENR25 latex especially the prevulcanisation time.

\section{II.MATERIAL AND METHOD}

\section{A. Materials}

The latex used in the present study is epoxidised natural rubber under trade name Ekoprena. It was obtained in latex form which is before the latex is further processed into dry rubber bale. The ENR latex has $25 \%$ epoxidation level and designated as ENR25. Its total solids content was $30 \%$. Potassium hydroxide $(\mathrm{KOH})$, potassium laurate, sulphur, ZDEC, zinc oxide $(\mathrm{ZnO})$ and antioxidant (Wingstay - L) were purchased from Merck, USA and used as received.

\section{B. Prevulcanisation of ENR25LlatexCcompound and} Curing of ENR25Latex

Accelerated sulphur vulcanisation system as described [9] as shown in Table 1was utilised in the present study. ENR25 latex was added into stainless steel vessel and stirred for 10 minutes at room temperature. All the vulcanisation ingredients were added into vessel in sequence.
TABLE 1

FORMULATION OF ENR25 LATEX VULCANISATION MiXES

\begin{tabular}{lc}
\hline \hline Ingredients & $\begin{array}{c}\text { In part per hundred } \\
\text { rubber, (p.h.r.) }\end{array}$ \\
\hline $30 \%$ ENR25 & 100 \\
$10 \% \mathrm{KOH}$ & 0.3 \\
$20 \% \mathrm{~K}$ - laurate & 0.3 \\
$50 \%$ sulphur & 0.5 \\
$50 \%$ ZDEC & 0.5 \\
$50 \%$ ZnO & 0.3 \\
$40 \%$ Wingstay L & 1.5 \\
\hline \hline
\end{tabular}

The latex compound was kept under slow stirring at room temperature for at least 30 minutes. About $120 \mathrm{~g}$ of compounded latex was then taken at 24 hours interval to study the prevulcanisation time. For 0 hour prevulcanisation time can be considered as 1 hour after complete addition of all vulcanisation ingredients prior sampling for casting. Cast films as shown in Fig. 1 were also obtained at each interval. The detail of the cast latex preparation is described elsewhere [10].
(A)

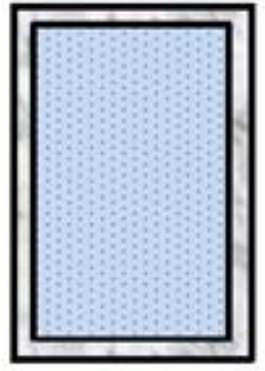

(C)

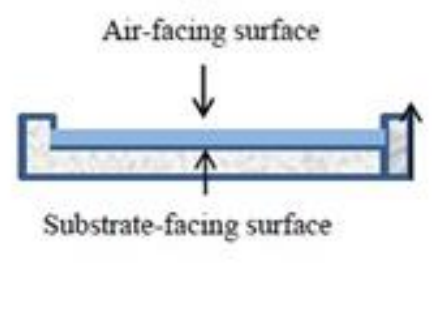

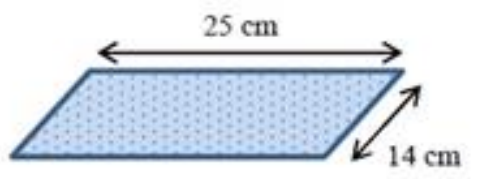

Fig. 1: The casting technique to prepare ENR25 film where (A) Glass plate mould (B) Cross-section of glass plate mould which showing air and substrate-facing surfaces, and (C) casted ENR25 film

\section{C.Latex Particles Morphology}

Unvulcanised ENR25 and prevulcanised ENR25 latex samples and distilled water were mixed in separate Eppendorf tubes prior to shaking for a few minutes. The mixtures were then centrifuged respectively. Osmium tetroxide was used to stain the samples. The morphology of unvulcanised and prevulcanised ENR25 latex particles were analysed using ESEM (FEI Quanta ${ }^{\mathrm{TM}} 50$ series, USA).

While for film formation and morphology of both unvulcanised and prevulcanised ENR25 films were examined under Light Microscope (Olympus BX51M, Japan) at 250V with $50 \mathrm{X}$ magnification. The films test piece were cut $(2 \mathrm{~cm} \mathrm{X}$ $2 \mathrm{~cm}$ ) respectively and put in the glass slide prior observed under optical light microscope.

\section{Solvent Swelling Measurement and Crosslinking}

\section{Density of Films}

Determination of swelling index was done via equilibrium volume swelling method, where the test pieces with dimension circular at $22 \mathrm{~mm}$ diameter was weighed and immersed in toluene in a glass bottles and left under ambient temperature of $25 \pm 3{ }^{\circ} \mathrm{C}$ for 0,24 and 48 hour. The swollen test piece was then removed and the excess toluene on surface was quickly blotted off using filter paper. The swollen sample was weighed in closed weighing bottle.

$$
\begin{aligned}
& \text { Swelling ratio }=\frac{\left(\mathrm{W}_{\mathrm{I}}-\mathrm{W}_{0}\right)}{\mathrm{W}_{0}} * 100 \\
& \text { Where; } \\
& \mathrm{W}_{1} \text { is weight of swollen rubber }(\mathrm{g}) \\
& \mathrm{W}_{0} \text { is weight of deswollen rubber }(\mathrm{g})
\end{aligned}
$$

For determination of crosslink density, after 48 hour swelling in toluene, the swollen test piece was then removed and the excess toluene on surface was quickly blotted off using filter paper. The swollen sample was weighed in closed weighing bottle. The sample was dried until constant weight. The crosslink density was determined by the Flory Rehner equation [11]. 


$$
-\ln (1-\mathrm{Vr})-\mathrm{Vr}-\chi \mathrm{Vr} 2=2 \rho \mathrm{V} 0 \text { nphysVr } 1 / 3
$$

\section{E. Films Tensile Strength}

Dumbbell test pieces cut from cast films were prepared using the type 2 die as described in the ISO 37 standard. Measurements of tensile strength were carried out on five film samples using an Instron Tensile Machine at a crosshead speed of $500 \mathrm{~mm} / \mathrm{min}$ with a $1 \mathrm{kN}$ load cell. Mean values

\section{RESULT AND DISCUSSION}

\section{A. Morphology of Latex Particles}

Fig. 2 shows the ESEM images for unvulcanised and vulcanised ENR25 latex particles. The figures shown are taken at magnification of $50,000 \mathrm{X}$ which were found to be necessary to for good observation of latex particles morphology and overall sizes. Fig. 2 (A) shows the particles size distribution of ENR25 can be divided to two types of particles size which are large particles $(c a 0.7 \mu \mathrm{m})$ and small particles $(\mathrm{ca} 0.1 \mu \mathrm{m})$. Similar occurrence was reported by Suteewong and Tangboriboonrat in 2007 [12], where the broad particles size distribution of ENR with a large average size. However as a comparison, the ENR25 latex particles seemed to be deformed and merged after prevulcanised as shown in Fig. 2 (B). The structure of the prevulcanised latex particles is suspected to be reminiscent of the influx of vulcanising reagents in the rubber particles. The influx of these reagents into the interior of the latex particles is deemed as a prerequisite for cross-linking to occur as described by Loh, 1982 [8]. It was reported that during prevulcanisation, rubber molecules cross-linking activity has taken place inside discrete rubber particles dispersed in the aqueous phase [5]. The structure of the prevulcanised ENR25latex particles has never been observed before hence a comparison cannot be made for the occurrence observed in the present study with current literatures. Nevertheless, this finding would provide some insights on the changes of the ENR25 latex particles morphology after prevulcanisation.

Fig. 3 represents light microscopy images of ENR25 films at the air-facing (AF) surfaces taken at $0,24,48$ and 72 hours of prevulcanisation time. As shown in the figures, the films surfaces at the prevulcanisation of 0 and 24 hours exhibited smoother and coherence surface compared to 48 and 72 hours prevulcanisation time. Films at the latter prevulcanisation time showed coarser and more undulating surface. The difference in the morphology of ENR25 films may reflect the difference in film formation at the stage where the particle coming into close contact with each other prior to coalescence. Hence, it could be suggested that the deformation and merging particles size of ENR25 latex particles at longer prevulcanisation time can be attributed to the formation of coarser and more undulating surfaces.

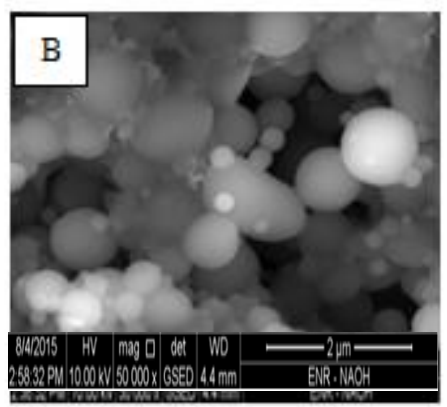

Fig. 2: ESEM micrograph images showing morphology of latex particles. (A) ENR25 and (B) ENR25 latex particles after 72 hours prevulcanisation time
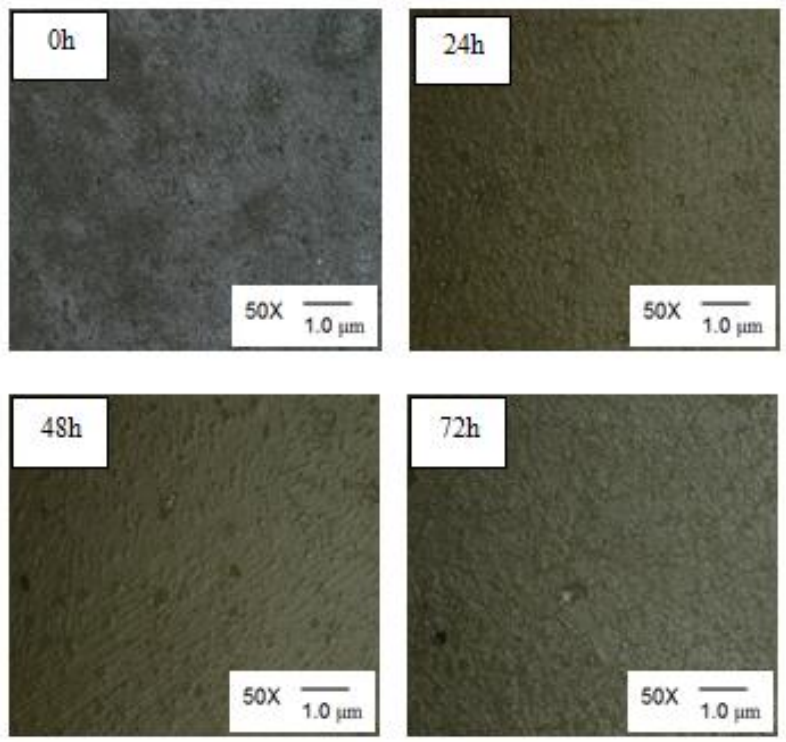

Fig. 3: Optical light micrographs of vulcanised ENR25 films at various prevulcanisation time 


\section{B. Solvent swelling and crosslinking density}

Solvent swelling measurement is a measure of the effect of the solvents and the resulting change in volume of a test sample which is exposed to solvents. For a rubber vulcanizate against a given solvent, the effect of solvents during swelling measurement could be defined as macroscopic volume change, associated with rubber- solvent and rubber-filler interaction [13]. Generally, during swelling in rubber vulcanized, diffusion of the solvent into rubber matrix expands the rubber network and thus weakens the molecular interaction between chains. Fig. 4 shows the changes swelling percentages of ENR25 films against prevulcanisation time. Swelling of ENR film was shown to slightly decrease with longer prevulcanisation time. Unvulcanised ENR film was taken as the control and it exhibited the highest swelling. For unvulcanized ENR25 film, solvent molecules could easily flow into the network chains which are not crosslinked. Relative to vulcanized ENR25 film, the rubber chains are crosslinked together chemically and restricted the movement of solvent molecules.

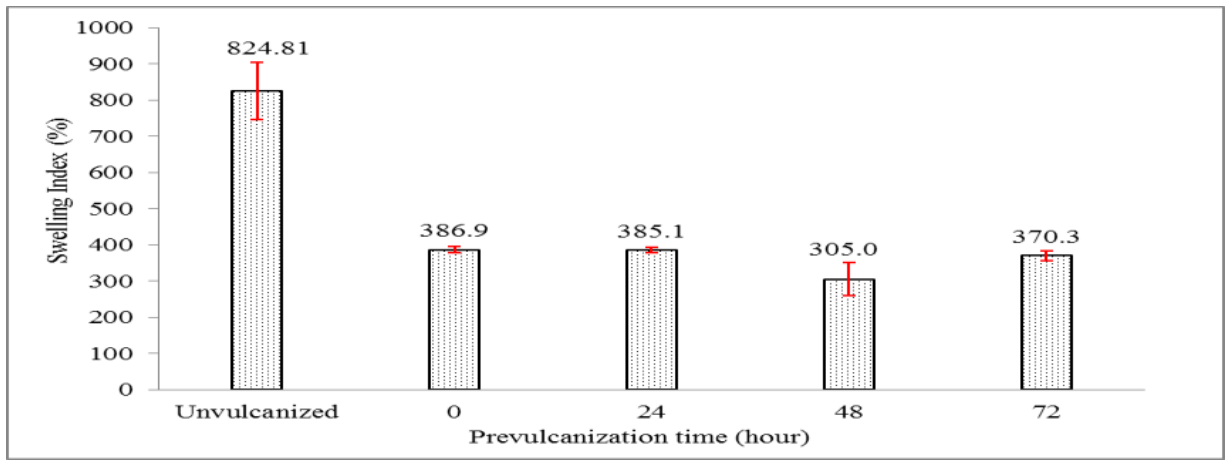

Fig. 4: Swelling index at equilibrium of unvulcanized and vulcanized ENR25 films

It is worthy to take note that the average of molecular weight between crosslinks, $\mathbf{M}_{\mathrm{c}}$ which one of the important parameter characterizing crosslinked polymers, is directly related to the crosslink density [14]. Significantly, the resulted $\mathrm{M}_{\mathrm{c}}$ affected the physical and mechanical properties of crosslinked polymer [14]-[15] which is useful to indicate the suitable use or intended applications of an elastomer. As such, numerous works has been focused on the effect of crosslinking density towards the properties of the polymers [16]-[17]. Similarly in the present study, crosslink density measurement was conducted to indicate the changes in crosslink density which be influenced by the duration of time in the prevulcanisation process.

Fig. 5 shows the crosslink density obtained from the solvent swelling method. The results indicated an increase in crosslink formation after 24 hours prevulcanisation time. Nevertheless, with the increase of prevulcanisation time, the crosslink density did not increased considerably after 48 prevulcanisation hours. Thus, it could be suggested that 24 hours prevulcanisation time is adequate to achieve the effective crosslinking in ENR25 film. Theoretically, when the swelling index is reduced the crosslink density is increased due to denser network chain and restriction in chain mobility. Similar trend could be observed in Nandi and Winter work [18] where with increase of crosslink density, the swelling index is reduced by modelling of poly ethylene irradiated by electron radiation and this also supported by Ruhida et al. [19] where the swelling resistance is increased with increasing crosslink density of NR latex films.

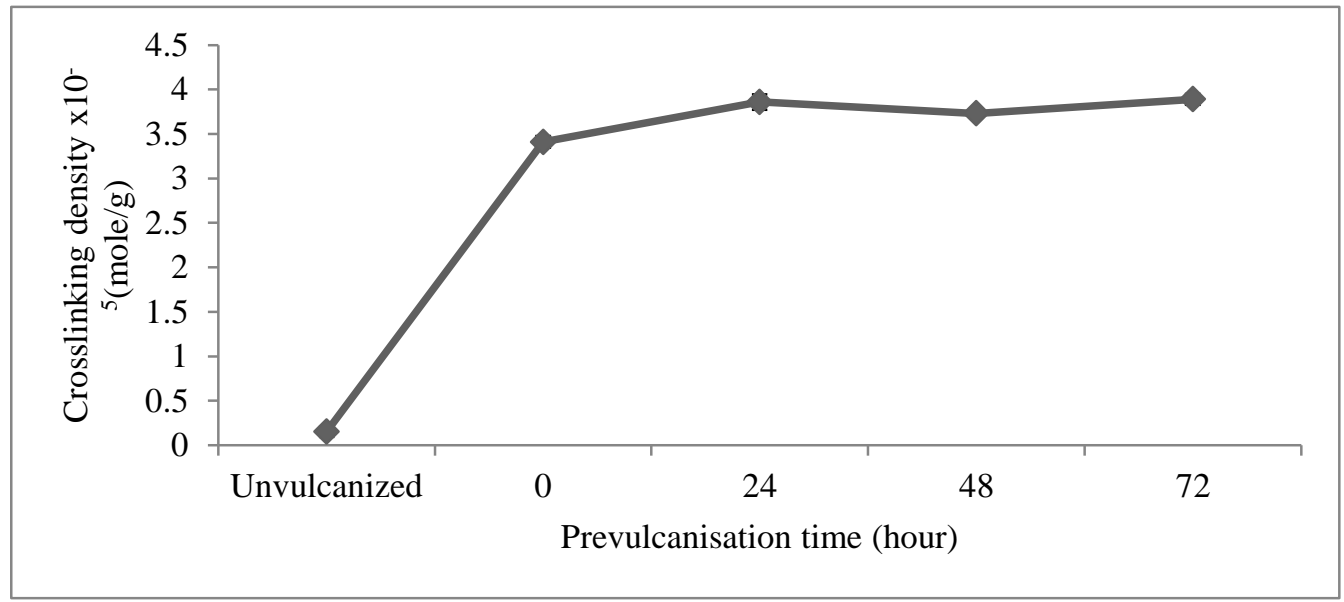

Fig. 5: Crosslink density of unvulcanised and vulcanised ENR25 films 


\section{C.Tensile strength}

The tensile strengths of unvulcanised and vulcanised ENR25 latex films at different prevulcanisation time are shown in Fig. 6. Increment in tensile strength can be seen in the ENR25 film even though sampling was carried at 1 hour after complete compounding. Based on the results, the tensile strength for 24 and 48 hours prevulcanisation time were fairly similar. Unvulcanised ENR25 films exhibited the lowest tensile strength due to the nonexistence of any chemical crosslinking in its rubber network. The tensile strength of ENR25 film was shown to increase markedly with increasing prevulcanisation time. The improvements observed in the tensile strength of the ENR25 latex films could be attributed to denser network chain and restriction in chain mobility.

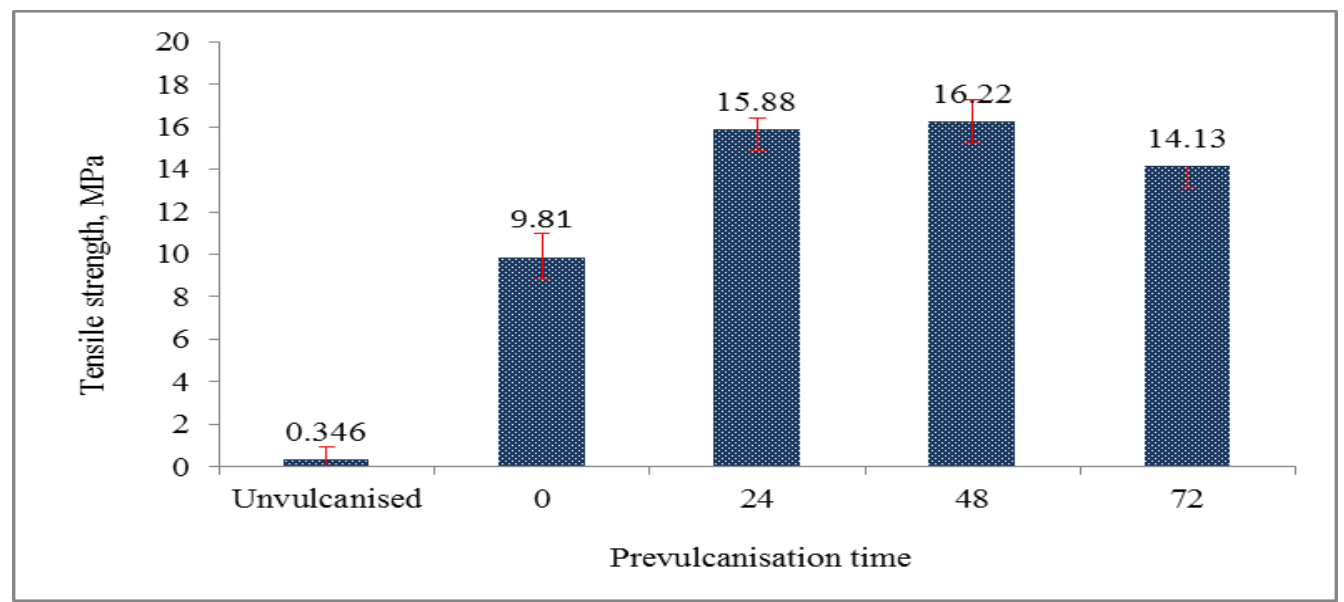

Fig. 6: The tensile strength measurement of ENR25 films against prevulcanisation time

After 48 hours prevulcanisation time, the tensile strength of films decreased and it is probably a consequence of decreasing ability of latex particles to coalesce and fully integrate as the concentration of crosslinks in the particle increases. According to Merrill, the occurrence is caused by poorly coalescing latex particles which inhibited further interparticles coalescence [20]. This will eventually results in poor films coherence. The results are in agreement where their result reflected that over-matured latex will cause poor film formation and premature rupture latex films [4]. Another proposed theory on the poor film formation obtained from over mature latex film is the reversion of vulcanisation [1]. Nonetheless, the present study lacks to indicate that the decrease in tensile strength after 48 hours is a consequent of vulcanisation.

\section{CONCLUSION}

In the present investigation, it is shown that the latex morphology of ENR25 latex after prevulcanisation exhibited deformed and merged particles of rubber latex. Film surface of ENR25 films also displayed changes from relatively smoother to coarser surfaces as prevulcanisation time increased. For the tensile strength and crosslink results showed increment as prevulcanisation time increases. However after 48 hours, the tensile strength of films decreased. These findings may indicate that in the ENR25 latex prevulcanisation, time is an important parameter which must be controlled to achieve the desirable film surface morphology as well as physical properties of films. Thus, it can be suggested that the most suitable prevulcanisation time for ENR25 latex is 24 hours in order to counterbalance the properties between surface morphology, film coherence and tensile strength properties of the resulting ENR25 latex films.

\section{ACKNOWLEDGMENT}

Technical assistance rendered by Nurul Fariha Poudzi and Aminah Mohamed Ayub of Rubber Research Institute of Malaysia (RRIM) is gratefully acknowledged. The author is also would like to extend gratitude to Malaysian Rubber Board for approval of funding and permission to publish this research work.

\section{REFERENCES}

[1] D. C. Blackley, Polymer Latices Science \& Technology: Volume 2 Types of Latices. Chapman \& Hall, 1997, Volume 2: $2^{\text {nd }}$ Edition, p. 449.

[2] A. D. T. Gorton, The production and properties of prevulcanised natural rubber latex. Natural Rubber Technology. 1979, Vol. 10, Part 1.

[3] Porter, M., Rawi, R. and Sapi'ai Abdul Rahim. Chemistry of the Latex Prevulcanisation Process. Part 1: Migration of Reactants from the Solid Phase info Rubber Particles. J. Nat. Rubb. Res., 1992, Vol 7 (2), p.85100.

[4] Nurulhuda Abdullah and Amir Hashim, M. Y. Film Formation in Rubber Gloves. Malaysian Rubber Technology Developments: Developments within the Glove Industry. 2014, Volume 14 (1). P 16-20.

[5] Ho, C. C. and Khew, M. C. Surface Morphology of Prevulcanised Natural Rubber Latex Films by Atomic Force Microscopy: New insight into the Prevulcanisation Mechanism. Langmuir. 1999, Vol. 15, p. 6208-6219. http://dx.doi.org/10.1021/la981601v

[6] Cook, S., Cudby, P. E. F., Davies, R. T. and Morris, M. D. The microstructure of Natural Rubber Latex Films. Rubber Chemistry Technology. 1997, Vol. 70, p. 449-559. http://dx.doi.org/10.5254/1.3538442

[7] Jacqueline, S. (1998). Study of Postvulcanisation of Natural Rubber Latex. PhD Thesis, Loughborough University, UNITED KINGDOM.

[8] Loh, A. C.-P. (1982). Further Investigations of the Prevulcanisation of Natural Rubber Latex. Phd Thesis. The North London Polytechnic, London. 
[9] Siti Nor Qamarina, M. and Amir Hashim, M. Y. Zinc-Complexes in Natural Rubber Latex Sulphur Vulcanisation System. J. Rubb. Res., 2009, Vol. 12 (2), p. 80-92.

[10] Ruslimie, C. A. and Asrul, M. The occurrence of phase separation in microcrystalline cellulose filled natural rubber films. Advance Material Research Conference, Bayview Hotel, Langkawi. 25-26 Nov. 2014.

[11] Mullins, L. Determination of Degree of Crosslinking in Natural Rubber Vulcanisates, Part 1, J, Polym. Sci. 1956, XIX, 223-236.

[12] Suteewong, T. and Tangboriboonrat, P. Particles Morphology of Epoxidised Natural Rubber Latex Prevulcanised by Peroxide System. 2007, e-polymer., Vol. 7(1), p. 1409-1417.

[13] Fukumori, K. Kurauchi, T. and Kamogaito, O., Swelling behaviour of rubber vulcanizates: 1. Real-time pulsed nuclear magnetic resonance measurement, 1990, Polymer, Vol 31.

[14] Ding, Z.Y. Aklonis, J.J and Salovey, R., Model Filled Polymer. VI. Determination of the crosslink density of polymeric beads by swelling, $J$. Polym Sci. Part B: Polym Phys. 1991, Vol 29. 1035-1038 http://dx.doi.org/10.1002/polb.1991.090290815

[15] Wang, Y., Wang, S., Bian, C., Zhong, Y., Jing, X. Effect of Chemical Structure and Cross-link Density on the Heat Resistance of Phenolic Resin. Polymer Degradation and Stability. 2015, Vol. 111. 239-246. http://dx.doi.org/10.1016/j.polymdegradstab.2014.11.016

[16] Siti Nor Qamarina Manaf and Kawahara, S., Effect of Mg Oxide nanoparticles on Sulphur Vulcanisation of Natural Rubber. J. Rubb. Res. 2014, 17(1). 13-22

[17] Asrul M., Zakaria M, Fauzi M.S., Surface morphology and tensile strength of natural rubber films filled with sulphur free lignin derived from rubberwood. J Rubber Res. 2013, 16(2). 118-133

[18] Nandi S. and Winter H.H., Swelling Behaviour of Partially Cross-linked Polymers: A Ternary System, Macromolecules. 2005, Vol. 38. 44474455. http://dx.doi.org/10.1021/ma048335e

[19] Ruhida A.R. Azemi S. Amir Hashim M.Y. (1998). Swelling Resistance and Tensile Strength of Natural Rubber (NR) and Carboxylated NitrileButadiene Rubber (XNBR) Latex Blends, Speciality Polymers. Springer - Verlag. 8-19.

[20] Merrill, R. W. T. (1980). Prevulcanisation of Natural Rubber Latex, M. Phil. Thesis, United Kingdom Council for National Academic Awards. 